\title{
CORNER FIRE GROWTH IN A ROOM WITH A COMBUSTIBLE LINING
}

\author{
Brian Y. Lattimer, Sean P. Hunt, Mark Wright, and Craig Beyler \\ Hughes Associates, Inc. \\ 3610 Commerce Drive, Suite 817 \\ Baltimore, Maryland 21227, USA
}

\begin{abstract}
The flammability of interior finish materials for many applications is regulated using the ISO 9705 large-scale room corner fire test. To aid designers in developing new materials, a fire growth model has been developed to predict material performance in the ISO 9705 test using small-scale test data from ASTM E1354 cone calorimeter. The fire growth model includes a flame spread model linked with a two zone compartment fire model, CFAST Version 3.1.2. At a user selected time interval, the flame spread model uses the gas temperature from CFAST to predict the heat release rate of the fire at that time interval, and then provides CFAST with a new heat release rate to predict conditions during the next time step. The flame spread model is an improved version of the flat wall flame spread model previously developed for the U.S. Navy. The model is capable of predicting flame spread in a variety of configurations including a flat wall, a corner with a ceiling, flat wall with a ceiling, unconfined ceiling, and parallel walls. The fire growth model was used to predict the heat release rate and smoke production rate measured in eight ISO 9705 room corner fire tests on composite materials used in marine applications.
\end{abstract}

KEYWORDS: corner flame spread modeling, ISO 9705 simulations, room fire growth, heat flux correlations, composite materials

\section{INTRODUCTION}

Composite materials are being considered for an increasing number of applications in all types of transportation vehicles. To aid material designers in evaluating the performance of innovative materials, Beyler et al. [1] explored methods for the U.S. Coast Guard (USCG) that use small-scale fire test data to predict material performance in the ISO 9705 large-scale room corner fire test [2]. One of the methods evaluated was the use of state-of-the-art fire growth models in predicting the conditions that develop during an ISO 9705 room corner fire test. Input data for these models are developed using small-scale fire test data, such as data from ASTM E1354 cone calorimeter [3]. In this program, there was particular interest to evaluate how well these models could predict the heat release rate and smoke production rate during the ISO 9705 test since these measurements are being used to regulate materials as "fire-restricting". Model performance was evaluated on two levels:

1. Comparison of the time history predictions of heat release rate and smoke production rate with conditions measured in the ISO 9705 fire tests, and

2. Comparison of predicted and measured time averaged heat release rate and smoke production rate since these parameters are used to regulate materials as "fire restricting".

Though such models would not replace conducting the large-scale test, models that could successfully predict material performance in the ISO 9705 test could aid material designers in determining whether large-scale testing is warranted.

One of the three models evaluated in the USCG program conducted by Beyler et al. [1] was the fire growth model developed by Hughes Associates, Inc. (HAI) for the U.S. Navy [4]. This paper provides a description of the most recent version of this fire growth model. Analysis was conducted on the model to evaluate its sensitivity to important input data and model settings. The model was then used to predict the fire growth in eight ISO 9705 room corner tests on different materials having a range of performance. The performance of the model was evaluated based on a 
comparison of time history and time averaged heat release rate and smoke production rate data with model results.

\section{FIRE GROWTH MODEL DESCRIPTION}

The fire growth model is capable of predicting fire conditions that develop during the pre-flashover stages of a compartment fire. The fire growth model consists of two linked programs: a flame spread program and a compartment fire model. The flame spread program is the Navy flame spread model developed by Beyler, et al. [5] and Lattimer et al. [4]. This model is used to calculate the contribution of wall linings to the growth of a fire inside a compartment. The compartment fire model is the two-layer, multi-compartment smoke spread model CFAST 3.1.2, which was developed by researchers at National Institute of Standards and Technology [6]. The two models were linked together so that the models can exchange information at a user selected time interval. Using the upper-layer gas temperature from CFAST, the flame spread model determines the cumulative burning area inside the compartment and the total heat release rate of the fire. CFAST uses this total heat release rate from the flame spread model to calculate the gas temperature, smoke levels, and combustion product concentrations throughout the area being analyzed over the next time interval.

\section{FLAME SPREAD PROGRAM DESCRIPTION}

The flame spread program within the fire growth model is a non-symmetric model capable of predicting two-dimensional flame spread and heat contribution from combustible walls and ceilings. The current version of this model is capable of predicting fire growth inside compartments lined with multiple combustible and noncombustible wall linings with the fire in different locations. The model accounts for the effects of compartment conditions on the flame spread along lining materials. Flame spread input data for the combustible boundary materials were developed from small-scale test data in the cone calorimeter [3]. The model has been validated against fire test data for flame spread over a vertical wall [5] and in a combustible corner with no hot layer [4].

The flame spread model divides the combustible surfaces being considered in the analysis into a user selected number of square, uniform size cells. During the fire each cell is considered to be in one of three stages : pre-heat, burning, or burnout. During the pre-heat stage, a heat transfer algorithm was used to predict the temperature rise of each cell with time [5]. The heat transfer algorithm was based on theory developed from assuming the material behaves as a semi-infinite solid with a cubic temperature profile through the material and a time varying heat flux boundary condition. The heat flux boundary condition is equal to the net heat flux into the material, which is determined from the heat flux correlations for the fire, hot gas layer heating, and reradiation losses. A cell is predicted to ignite when the surface temperature reaches the material ignition temperature. In the burning stage, the heat release rate of a cell is dependent on the net heat flux into the material and the fire properties of the cell material. The total heat release rate is determined by adding the heat released from all burning cells with the heat release rate of the initiating source fire. A cell is predicted to burnout when the total potential heat release has been expended.

\section{Flame Length and Heat Flux Correlations for the Corner Configuration}

The flame spread model requires the net heat flux at the boundary of the material surface. To calculate the net heat flux, the heat flux from the fire must be determined. For the corner configuration several heat flux correlations are necessary to describe the heat flux from a fire to the corner because of the three-dimensional nature of the fire. For modeling purposes, the corner was divided into the three regions noted in Fig. 1: the lower portion of the corner walls, the top portion of the walls near the ceiling, and the ceiling. Heat flux correlations were required for each direction of flame spread. Both the lower and top portion of the walls have two-dimensional flame spread. Therefore, several heat flux correlations were required to predict both the vertical and horizontal distribution in heat flux within these regions. On the ceiling, the flame spread was assumed to be one-dimensional radially out from the corner; therefore, heat flux correlations were required to predict the radial distribution in heat flux along the ceiling. 

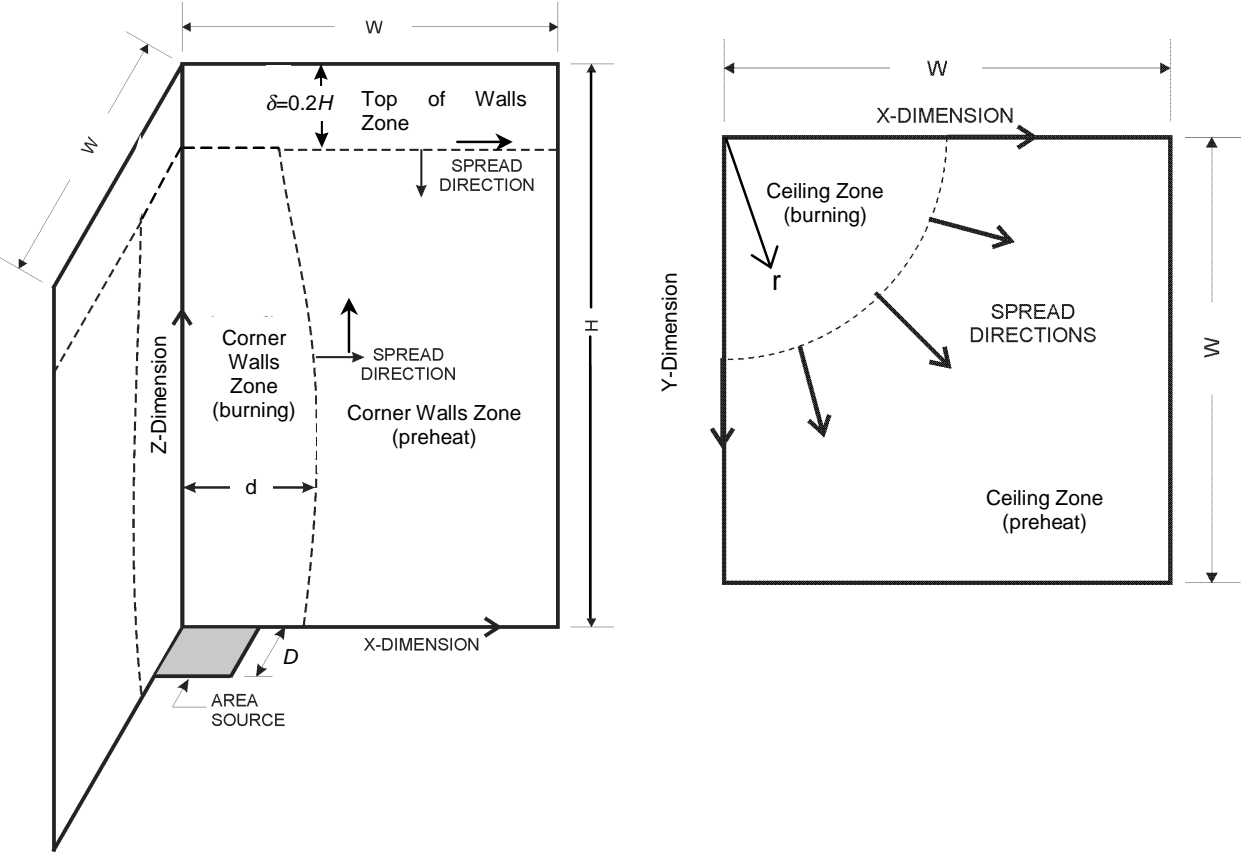

Figure 1. Corner configuration showing the different regions the corner is divided into for modeling flame spread.

Many of the heat flux correlations and the flame length correlation were based on data from the study conducted by Lattimer et al. [4]. In this study, fire tests were conducted in a $2.44 \mathrm{~m}$ high, 2.1 $\mathrm{m}$ wide non-combustible corner with a ceiling. Flame lengths, heat fluxes to the corner boundaries, and gas temperatures were measured with area sources in the corner and in separate tests with Lshaped line burners in the corner. L-shaped line burner tests were conducted to simulate conditions produced by burning boundaries. Area source fires were square sand burners $0.17-0.50 \mathrm{~m}$ on a single side, while L-shaped line burners were $0.17-0.50 \mathrm{~m}$ on a single side. All fires were produced using propane gas with heat release rates ranging from $25-300 \mathrm{~kW}$. Flame length and heat flux measurements were also made in three large-scale tests with a $0.17 \mathrm{~m}$ square burner (100 $\mathrm{kW}$ for 600 seconds and $300 \mathrm{~kW}$ for 600 seconds) in corner lined with a different combustible material in each test.

\section{Flame Length}

The flame tip length was the length of the flame in the corner plus any flame extension along the ceiling. The flame tip length was calculated using the relation developed by Lattimer et al. [4] through a series of corner fire tests with area source fires, L-shaped line burners and area source fires in a combustible corner. For all of these cases, the flame tip length was found to correlate to the following expression :

$$
L_{f, t i p}=5.9 Q_{d}^{* 1 / 2} d
$$

where $d$ is the width of the burning on a wall in the corner (m) and $Q_{d}^{*}$ is a dimensionless heat release rate parameter. In the early stages of the fire before the wall has ignited, the width of the burning on a corner wall, $d$, is equal to the burner diameter, $D$. After the boundary ignites and the flames propagate outside of the width of the burner, $d$ was taken to be the average width of flaming on the lower part of the wall $(z<0.8 H)$. The burning width at an elevation $0.9 \mathrm{~m}$ above the source 
fire was found in large scale tests to be representative of the average burning width. The dimensionless heat release rate parameter was calculated using the following relation,

$$
Q_{d}^{*}=\frac{Q}{\rho_{\infty} T_{\infty} C_{p} \sqrt{g} d^{5 / 2}}
$$

where $Q$ is the total heat release rate of the source fire and the walls $(\mathrm{kW}), \rho_{\infty}$ is the ambient density $\left(1.2 \mathrm{~kg} / \mathrm{m}^{3}\right), T_{\infty}$ is the ambient temperature $(300 \mathrm{~K}), C_{p}$ is the specific heat capacity of air $(1.0 \mathrm{~kJ} / \mathrm{kg}$ $\mathrm{K})$, and $g$ is the acceleration of gravity $\left(9.81 \mathrm{~m} / \mathrm{s}^{2}\right)$. Note that the heat release rate from the ceiling was excluded from the flame length calculation. This was done because all of the heat flux correlations were developed with fires located below the ceiling.

\section{Heat Flux to Lower Part of Corner Walls $(z<0.8 H)$}

The heat flux to the lower part of the walls $(z<0.8 H)$ was dependent on whether or not the walls had ignited. Prior to the walls igniting the incident heat flux to the walls is due to the area source fire. As wall material ignites, the heat flux to the surface becomes some combination of the heat fluxes generated by the area source fire and those generated by the corner wall fire. Heat flux correlations exist for an area source in the corner and for burning boundaries in the corner, but not for both in the corner at the same time. To model this situation, the model separately calculated the heat flux from the source (Eqs. 3, 4, and 5) and the heat flux due to the burning walls (Eqs. 6 and 7). At each cell, the incident heat flux was taken to be the higher of the two heat fluxes. A description of the heat flux correlations is provided below.

The incident heat flux to the wall from an area source fire located in the corner has been measured to vary with elevation above the source fire and the lateral distance from the corner [4, 7]. From Lattimer et al. [4], the maximum heat flux (in $\mathrm{kW} / \mathrm{m}^{2}$ ) varies with elevation above the base of the source fire according to the following equations:

$$
\begin{array}{ll}
q_{\text {max }}^{\prime \prime}(z)=q_{\text {peak }}^{\prime \prime} & \frac{z}{L_{f, \text { tip }}} \leq 0.40 \\
q_{\max }^{\prime \prime}(z)=q_{\text {peak }}^{\prime \prime}-4\left(\frac{z}{L_{f, \text { tip }}}-\frac{2}{5}\right)\left(q_{\text {peak }}^{\prime \prime}-30\right) & 0.4<\frac{z}{L_{f, \text { tip }}}<0.65 \\
q_{\max }^{\prime \prime}(z)=7.2\left(\frac{z}{L_{f, \text { tip }}}\right)^{-10 / 3} & \frac{z}{L_{f, \text { tip }}} \geq 0.65
\end{array}
$$

where $z$ is the target elevation above the base of the source fire $(\mathrm{m})$, and $L_{f, t i p}$ is the flame tip length (m) from Eqs. 1 and 2. The peak heat flux, $q_{\text {peak }}^{\prime \prime}$, measured in the lower half of the flame was determined to be a function of the source diameter and was determined (in $\mathrm{kW} / \mathrm{m}^{2}$ ) through the following equation [4]:

$$
q_{\text {peak }}^{\prime \prime}=120[1-\exp (-4 D)]
$$

where $D$ is the diameter of the source fire $(\mathrm{m})$.

The heat flux to the corner walls decreases with horizontal distance from the corner. For area source fires, the heat flux distribution on the corner walls was measured by Lattimer et al. [4] to have a half-Gaussian shape distribution and was predicted (in $\mathrm{kW} / \mathrm{m}^{2}$ ) through the following correlation,

$$
q^{\prime \prime}(x, z)=q_{\max }^{\prime \prime}(z) \exp \left(-7.5 x^{2}\right)
$$

where $q_{\max }^{\prime \prime}(z)$ is the maximum heat flux from an area source fire to the corner walls $\left(\mathrm{kW} / \mathrm{m}^{2}\right)$ from Eq. 3 and $x$ is the distance from the corner (m). 
The heat flux from burning corner walls was determined using heat flux data from different size Lshaped line burners in a corner with a ceiling [4]. From these tests, the vertical distribution in the maximum heat flux to the corner walls was predicted (in $\mathrm{kW} / \mathrm{m}^{2}$ ) using the following relations:

$$
\begin{array}{ll}
q_{\max }^{\prime \prime}(z)=70 & \left(z / L_{f, t i p}\right)<0.5 \\
q_{\max }^{\prime \prime}(z)=10.0\left(z / L_{f, t i p}\right)^{-2.8} & \left(z / L_{f, t i p}\right)>0.5
\end{array}
$$

where $L_{f, t i p}$ is the flame length (m) from Eqs. 1 and 2. Heat flux levels were measured to decrease with horizontal distance from the corner. The horizontal heat flux distribution was also found to be half-Gaussian in shape and was predicted (in $\mathrm{kW} / \mathrm{m}^{2}$ ) through the correlation below:

$$
q^{\prime \prime}(x, z)=q_{\max }^{\prime \prime}(z) \exp \left[-1.0(x / d)^{2}\right]
$$

where $q_{\max }^{\prime \prime}(z)$ maximum heat flux to the corner walls from the burning wall itself determined using Eq. 6 and $d$ is the width of the burning on the corner wall.

Burning wall elements were assumed to have a heat flux from the fire of no less than $60 \mathrm{~kW} / \mathrm{m}^{2}$. This is consistent with heat fluxes measured in the L-shaped line burner tests in the lower part of the flame $\left(z / L_{f, t i p}<0.5\right)$ where flames were continuous [4]. This is also consistent with peak heat fluxes measured for wall fires from high soot producing fuels [8].

\section{Heat Flux to Top of Walls Near the Ceiling $(0.8 H \leq z \leq H)$}

When a ceiling is present, hot gases from the fire plume are redirected away from the corner resulting in a ceiling jet flowing along the ceiling and the top part of the walls. This ceiling jet flow results in elevated heat fluxes along the top part of the wall $(0.8 H \leq z \leq H)$. Lattimer et al. [4] measured heat fluxes along the top part of the walls in a corner configuration in fire tests with area sources in the corner and with L-shaped line burners in the corner. For both types of fires, maximum heat flux levels were measured near the ceiling (less than $0.075 \mathrm{~m}$ below the ceiling). Heat fluxes decayed with both distance from the corner and with distance below the ceiling.

Lattimer et al. [4] found that a single set of correlations could be used to predict the heat flux distribution along the top part of the walls, independent of whether the fire is an area source or an L-shaped line burner (burning boundaries). The maximum heat flux along the top of the walls was predicted (in $\mathrm{kW} / \mathrm{m}^{2}$ ) through the following correlations :

$$
\begin{array}{ll}
q_{\text {max }}^{\prime \prime}=120 & (x+H) / L_{f, t i p} \leq 0.58 \\
q_{\text {max }}^{\prime \prime}=18\left[(x+H) / L_{f, t i p}\right]^{-3.5} & (x+H) / L_{f, t i p}>0.58
\end{array}
$$

where $x$ is the horizontal distance from the corner $(\mathrm{m}), H$ is the distance between the fire $(\mathrm{m})$ and the ceiling, and $L_{f, t i p}$ is the flame length (m) from Eqs. 1 and 2.

Heat fluxes on the top of the walls decreases with distance below the ceiling. The rate of decrease is dependent on distance away from the corner and was predicted (in $\mathrm{kW} / \mathrm{m}^{2}$ ) through the following relations :

$$
\begin{array}{ll}
q^{\prime \prime}=q_{\text {max }}^{\prime \prime} & x \leq 0.20 \\
\left.q^{\prime \prime}=q_{\text {max }}^{\prime \prime} \exp \{-(x-0.20)[(H-z)) / \delta]\right\} & 0.20<x \leq 0.60 \\
\left.q^{\prime \prime}=q_{\text {max }}^{\prime \prime} \exp \{-0.41[(H-z)) / \delta]\right\} & x>0.60,
\end{array}
$$

where $q_{\max }^{\prime \prime}$ is the maximum heat flux along the top of the walls $\left(\mathrm{kW} / \mathrm{m}^{2}\right)$ from Eq. $8, x$ is the horizontal distance from the corner $(\mathrm{m}), H$ is the distance between the fire and the ceiling $(\mathrm{m}), z$ is the vertical distance above the fire (m), and $\delta=0.1 H$ is the ceiling jet depth (m) [9]. Near the corner heat fluxes are constant, while in the turning region of the ceiling jet $(0.20<x<0.60)$ the decay in the heat flux is dependent on the distance from the corner. After the turning region $(\sim x=0.60 \mathrm{~m})$, the decay in heat flux below the ceiling was measured to be constant. 
Based on large-scale fire testing with a fire in a combustible corner [4], heat fluxes of burning cells near $\left(0.15 \mathrm{~m}\right.$ below) the ceiling on the top part of the walls were measured to be $40-50 \mathrm{~kW} / \mathrm{m}^{2}$. In the model, burning cells along the top of the walls were assumed to have a heat flux of no less than $50 \mathrm{~kW} / \mathrm{m}^{2}$.

\section{Heat Flux to Ceiling}

Hot gases from the corner fire impinge on the ceiling in the corner and then are redirected to flow radially out from the corner along the ceiling. Heat fluxes from the hot gases flowing along the ceiling decrease with radial distance from the corner [4,10]. Lattimer et al. [4] determined that the heat flux distribution on the ceiling can be predicted using a single set of correlations, independent of whether the fire is an area source or an L-shaped line burner (burning boundaries). The heat flux distribution on the ceiling was determined (in $\mathrm{kW} / \mathrm{m}^{2}$ ) using the following correlations :

$$
\begin{array}{ll}
q^{\prime \prime}=120 & (r+H) / L_{f, t i p} \leq 0.58 \\
q^{\prime \prime}=18\left[(r+H) / L_{f, t i p}\right]^{-3.5} & (r+H) / L_{f, \text { tip }}>0.58,
\end{array}
$$

where $r$ is the radial distance from the corner $(\mathrm{m}), H$ is the distance between the fire and the ceiling $(\mathrm{m})$, and $L_{f, t i p}$ is the flame length (m) from Eqs. 1 and 2. This is the same correlation used to predict the maximum heat flux to the upper part of the walls, except the $x$ is replaced with $r$.

Based on large-scale fire testing with a fire in a combustible corner [4], heat fluxes of burning cells on the ceiling were not measured to be less than $20-30 \mathrm{~kW} / \mathrm{m}^{2}$. This is relatively consistent with the burning ceiling testing done by Hasemi et al. [11], where heat fluxes were measured to be as high as $20 \mathrm{~kW} / \mathrm{m}^{2}$. In the model, burning cells along the ceiling were assumed to have a heat flux of no less than $30 \mathrm{~kW} / \mathrm{m}^{2}$.

\section{Hot Gas Layer Effects}

A hot gas layer adjacent to the boundary will increase the net heat flux into the material. The net heat flux to the surface was calculated using a heat balance at the surface,

$$
q_{\text {net }}^{\prime \prime}=q_{f}^{\prime \prime}+q_{\text {layer }}^{\prime \prime}-q_{\text {loss }}^{\prime \prime}
$$

where, $q_{f}^{\prime \prime}$ is the heat flux from the fire $\left(\mathrm{kW} / \mathrm{m}^{2}\right), q_{\text {layer }}^{\prime \prime}$ is the heat flux due to the hot layer inside the compartment $\left(\mathrm{kW} / \mathrm{m}^{2}\right), q_{\text {loss }}^{\prime \prime}$ is the heat losses from the material surface $\left(\mathrm{kW} / \mathrm{m}^{2}\right)$. Based on data from Tanaka et al. [12], the hot gas layer was treated as a radiant source emitting as nearly a blackbody,

$$
q_{\text {net }}^{\prime \prime}=q_{f}^{\prime \prime}+\varepsilon_{\text {layer }} \sigma T_{\text {layer }}^{4}-\varepsilon_{s} \sigma T_{s}^{4}
$$

where, $\varepsilon_{\text {layer }}$ is the emissivity of the layer $\left(\varepsilon_{\text {layer }}=0.95\right), \sigma$ is the Stefan-Boltzman constant $(\sigma=5.67 \mathrm{x}$ $\left.10^{-11} \mathrm{~kW} / \mathrm{K}^{4}\right), T_{\text {layer }}$ is the gas layer temperature inside the room $(\mathrm{K})$, and $\varepsilon_{s}$ is the emissivity of the surface $\left(\varepsilon_{s}=0.95\right)$. The gas layer temperature was the upper-layer gas temperature calculated in CFAST at the previous time step, while heat losses by the surface were based on the surface temperature in the previous time step. The heat flux from the fire was determined from the empirical heat flux correlations for the scenario being analyzed. For the corner configuration considered here, the heat flux correlations outlined in the previous sections were used to determine the heat flux from the fire.

\section{Cell Heat Release Rate and Burnout}

The heat release rate of the cell was assumed to be dependent on the net heat flux and the fire properties of the material. An approach developed by Mitler and Steckler [13] was used to calculate the heat release rate of a cell exposed to a time varying heat flux. In this method, a reference heat release rate curve is scaled to quantify the heat release rate of a cell at a particular time knowing the net heat flux into the material. The general shape of the heat release rate curve is assumed to be unaffected by the net heat flux on the material. However, a change in heat flux would alter the duration of burning and magnitude of heat release rate. For example, a net heat flux level greater than the reference net heat flux would result in a higher heat release rate but a shorter 
burning duration. The reference heat release rate curve was developed from a cone calorimeter test performed at an irradiance of 50 or $75 \mathrm{~kW} / \mathrm{m}^{2}$. A cell was predicted to burnout when the potential total heat release has been expended.

\section{Material Fire Property Data}

The fire growth model requires material fire property data to describe the performance of the material. These input data include ignition temperature $\left(T_{i g}\right)$, effective thermal inertia for ignition $(k \rho C)$, heat release rate of the material at a known irradiance level, and total heat released.

The ignition temperature, $T_{i g}$, was calculated using the critical heat flux found in the cone calorimeter and an energy balance at the material surface at ignition,

$$
q_{c r}^{\prime \prime}=\varepsilon_{s} \sigma\left(T_{i g}^{4}-T_{o}^{4}\right)+h_{c}\left(T_{i g}-T_{o}\right)
$$

where $q_{c r}^{\prime \prime}$ is the critical heat flux for ignition $\left(\mathrm{kW} / \mathrm{m}^{2}\right), \varepsilon_{s}$ is the material surface emissivity ( $\left.\varepsilon_{s}=0.95\right), T_{o}$ is the ambient temperature $\left(T_{o}=298 \mathrm{~K}\right)$, and $h_{c}$ is the convective heat transfer coefficient $\left(h_{c}=0.015 \mathrm{~kW} / \mathrm{m} \cdot \mathrm{K}\right)$.

The effective thermal inertia for ignition, $k \rho C$, was developed using the ignition model within the flame spread model and the ignition data from the ASTM E1354 cone calorimeter at different irradiance levels. The $k \rho C$ for the material was taken to be the value at which the model adequately predicted the cone calorimeter ignition data.

Species input data for the compartment fire model were developed from yields measured in the ASTM E1354 cone calorimeter. The $\mathrm{CO}-\mathrm{CO}_{2}$ mass ratio was determined by dividing the $\mathrm{CO}$ yield with the $\mathrm{CO}_{2}$ yield, while the carbon (C)-CO mass ratio was determined by dividing the $\mathrm{C}$ yield by the $\mathrm{CO}_{2}$ yield. Using results from Seader and Einhorn [14], the smoke specific extinction area, $\sigma_{s m k}$, from the cone calorimeter was used to determine the carbon yield :

$$
Y_{C}=\frac{\sigma_{s m k}}{7670}
$$

\section{MODEL SENSITIVITY ANALYSIS}

A sensitivity analysis was conducted on some of the data used to develop model parameters and some of the model settings. This analysis included the sensitivity of the model to the ignition data, heat release rate data, ignition temperature, smoke and other species yields, and flame spread model time step and grid size.

The model results are sensitive to the ignition data. The ignition data are used to determine the $k \rho C$ and essentially calibrate the ignition model for the material being analyzed. Errors in this data, even within the repeatability range stated in the ASTM E1354 [3] standard, can result in significant changes in the predictions. In this study the average ignition time at each irradiance was used to develop the $k \rho C$; however, the range of ignition data could be also used to evaluate the potential variability in the predictions.

The model uses a measured heat release rate curve as input, and the results are sensitive to this heat release rate curve. However, only marginal differences were observed when using a heat release rate curve from a test at an irradiance of $50 \mathrm{~kW} / \mathrm{m}^{2}$ as opposed to a curve measured at an irradiance of $75 \mathrm{~kW} / \mathrm{m}^{2}$. In this study the average heat release rate curve from multiple tests at an irradiance of 50 or $75 \mathrm{~kW} / \mathrm{m}^{2}$ was used in the simulations; however, bounding heat release rate curves could be used to assess the potential variability in the model results.

The model was found to be relatively insensitive to an accurate determination of the ignition temperature. It was determined that bracketing the critical flux by $\pm 3 \mathrm{~kW} / \mathrm{m}^{2}$ showed no appreciable difference in the results. This insensitivity is attributed to how the model is calibrated 
to the ignition data. When the ignition temperature is changed, the $k \rho C$ changes so that the model accurately predicts the ignition data. This result indicates that if ignition data exists at several heat fluxes and a reasonable estimate of the ignition temperature can be made, the model will provide a reasonable estimate of the material performance in the ISO 9705 room corner test.

The predicted heat release rate is sensitive to the predicted layer temperature. The layer temperature was found to be sensitive to the carbon (C)- $\mathrm{CO}_{2}$ mass ratio, assumed radiative fraction, and the fire location. Changing the $\mathrm{CO}-\mathrm{CO}_{2}$ mass ratio or the hydrogen-to-carbon mass ratio of the fuel did not significantly affect the results, but changing the $\mathrm{C}-\mathrm{CO}_{2}$ mass ratio (i.e., changing the smoke yield) did affect the layer temperature. Increasing the $\mathrm{C}-\mathrm{CO}_{2}$ mass ratio (higher smoke yields) resulted in lower gas temperatures. For example, increasing the $\mathrm{C}-\mathrm{CO}_{2}$ ratio from 0.010 to 0.120 resulted in a $75 \mathrm{~K}$ temperature drop. The gas temperatures predicted in the model were also sensitive to the assumed radiative fraction of the fire, and a radiative fraction of 0.10 yielded the best overall results. Gas temperatures predicted by CFAST were consistent with temperatures measured $0.10 \mathrm{~m}$ below the ceiling.

The model results were sensitive to using too large a time step or too large of a grid size. For time steps up to 2.0 seconds, there was no appreciable difference in the model results. For the ISO 9705 simulations, a grid size of as large as $0.20 \mathrm{~m}$ could be used without affecting the model results.

\section{ISO 9705 ROOM CORNER TEST MODELING RESULTS}

The fire growth model has been validated against a series of ISO 9705 room corner fire tests conducted for the USCG on the eight different composite materials listed in Table 1 [15]. Also included in Table 1 are some fire performance data for these materials. Simulations were conducted using the standard ISO 9705 room dimensions, which are $2.44 \mathrm{~m}$ high, $2.44 \mathrm{~m}$ wide and $3.66 \mathrm{~m}$ wide with a door $0.8 \mathrm{~m}$ wide and $2.0 \mathrm{~m}$ high. To replicate test conditions, simulations were conducted with the composite lining material over top of $0.020 \mathrm{~m}$ thick calcium silicate board. The initiating fire was a $0.17 \mathrm{~m}$ square burner in the corner with a heat release rate of $100 \mathrm{~kW}$ for 600 seconds followed by $300 \mathrm{~kW}$ for an additional 600 seconds, for a total test time of 1200 seconds. The only exception to this was the simulation of Material No. 1, where the heat release rate of the source during the last 600 seconds of the test was measured to decrease with time. For this simulation, the heat release rate was $100 \mathrm{~kW}$ for the first 600 seconds, $320 \mathrm{~kW}$ at 601 seconds, and linearly decreased to $225 \mathrm{~kW}$ at 1200 seconds. Flame spread calculations were conducted using square cell sizes of $0.10 \mathrm{~m}$ by $0.10 \mathrm{~m}$ and a time step of no larger than 1.0 second. Smoke production rates were determined using the door flow rate and the optical density of the upper-layer gases. The $\mathrm{CO}$ and $\mathrm{CO}_{2}$ yields were not measured using the ASTM E1354, so reasonable estimates of these parameters were used ( $\mathrm{CO}$ yield of 0.01 and $\mathrm{CO}_{2}$ yield of 1.5). The model performance was evaluated by comparing simulation results with both time averaged data and time history data.

Table 1. Description of composite materials.

\begin{tabular}{|c|c|c|c|c|c|c|c|}
\hline \multicolumn{2}{|r|}{ Material } & \multirow{2}{*}{$\begin{array}{c}\text { Resin } \\
\text { Content (\%- } \\
\text { mass) }[15]\end{array}$} & \multirow[b]{2}{*}{$T_{i g}(\mathrm{~K})$} & \multirow[b]{2}{*}{$k \rho C$} & \multicolumn{3}{|c|}{ Cone Data @ 75 kW/m² [15] } \\
\hline No. & Description & & & & $t_{i g}(\mathrm{~s})$ & $\begin{array}{c}\overline{Q^{\prime \prime}} \\
\left(\mathrm{kW} / \mathrm{m}^{2}\right)\end{array}$ & $\begin{array}{c}\bar{\sigma}_{s m k} \\
\left(\mathrm{~m}^{2} / \mathrm{kg}\right)\end{array}$ \\
\hline 1 & FR Phenolic $^{1}$ & 42 & 928 & 0.21 & 78 & 49 & 52 \\
\hline 2 & Fire Restricting Material $^{2}$ & 57 & 954 & 0.33 & 78 & 24 & 20 \\
\hline 3 & FR Polyester $^{3}$ & 45 & 694 & 0.47 & 27 & 72 & 729 \\
\hline 4 & FR Vinyl Ester ${ }^{3}$ & 42 & 694 & 0.58 & 34 & 84 & 1009 \\
\hline 5 & FR Epoxy $^{1}$ & 29 & 716 & 1.45 & 59 & 41 & 219 \\
\hline 6 & Coated FR Epoxy $^{1,4}$ & 29 & 836 & 0.35 & 30 & 23 & 242 \\
\hline 7 & Polyester $^{1}$ & 66 & 682 & 0.27 & 30 & 205 & 707 \\
\hline 8 & FR Modified Acrylic ${ }^{3}$ & 34 & 705 & 1.00 & 62 & 51 & 80 \\
\hline
\end{tabular}

1. Composite panels fabricated using wet layup process

2. Composite consists of a phenolic resin impregnated glass core with melamine facings

3. Composite panels fabricated using SCRIMP process

4. Coating is a $0.5 \mathrm{~mm}$ thick water-based intumescent coating 
A comparison of time average data with model results is shown in Table 2. IMO requirements [16] for a "fire-restricting material" are provided at the bottom of the table. To provide a consistent means for comparing the model results with the data, flashover was taken to be the time at which the heat release rate reached $1000 \mathrm{~kW}$. At this heat release rate, the occurrence of flashover inside the ISO 9705 room was assumed to be inevitable. Test average values were an average of all the data over the 1200 second test or up until the time at which flashover was considered to be reached. The 30 second average heat release rate was calculated by averaging the data over a sliding 30 second window for the duration of the test. The table includes the maximum 30 second average heat release rate. A similar approach was used for the maximum smoke production rate during the test except the window was 60 seconds.

The model was capable of predicting which lining materials caused the room to reach flashover and which did not. Overall, the predicted times to reach flashover were in good agreement with the data. The predicted times to reach flashover were within \pm 135 seconds of the data, except for Material No. 8 where flashover was predicted 222 seconds before it was observed in the test. The predicted average heat release rate values compare well with the test data. As one might expect,

Table 2. Summary of averaged results from the ISO 9705 test and the simulations.

\begin{tabular}{|c|c|c|c|c|c|c|c|c|c|c|}
\hline \multirow{3}{*}{ No. } & \multirow{2}{*}{\multicolumn{2}{|c|}{ 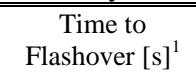 }} & \multicolumn{4}{|c|}{ Heat Release Rate [kW] } & \multicolumn{4}{|c|}{ SSmoke Production Rate [m²/kg] } \\
\hline & & & \multicolumn{2}{|c|}{ Test Average } & \multicolumn{2}{|c|}{ Max 30 s Avg. } & \multicolumn{2}{|c|}{ Test Average } & \multicolumn{2}{|c|}{ Max 60 s Avg. } \\
\hline & Test $^{2}$ & Model & Test $^{2}$ & Model & Test $^{2}$ & Model & Test $^{2}$ & Model & Test $^{2}$ & Model \\
\hline 1 & NR & NR & 62 & 61 & 159 & 179 & 1.5 & 3.2 & 5.4 & 5.6 \\
\hline 2 & NR & NR & 31 & 23 & 112 & 73 & 0.2 & 3.0 & 0.5 & 5.2 \\
\hline 3 & 342 & 475 & 203 & 217 & 677 & 697 & 9.4 & 14.1 & 21.7 & 35.1 \\
\hline 4 & 300 & 377 & 224 & 255 & 798 & 726 & 10.2 & 19.2 & 26.3 & 44.8 \\
\hline 5 & 1002 & 1008 & 125 & 118 & 454 & 686 & 6.7 & 5.0 & 26.4 & 15.7 \\
\hline 6 & NR & NR & 31 & 42 & 82 & 115 & 1.4 & 3.6 & 3.5 & 6.7 \\
\hline 7 & 102 & 44 & 170 & 152 & 402 & 188 & 2.3 & 1.3 & 2.7 & 1.3 \\
\hline 8 & 682 & 460 & 127 & 169 & 657 & 590 & 0.5 & 2.1 & 4.8 & 3.8 \\
\hline 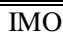 & & & \multicolumn{2}{|c|}{$\leq 100$} & \multicolumn{2}{|c|}{$\leq 500$} & \multicolumn{2}{|c|}{$\leq 1.4$} & \multicolumn{2}{|c|}{$\leq 8.3$} \\
\hline
\end{tabular}

1. Taken to be the time at which the heat release rate reached $1000 \mathrm{~kW}$.

2. Data from Reference [15].

$\mathrm{NR}=$ Not Reached

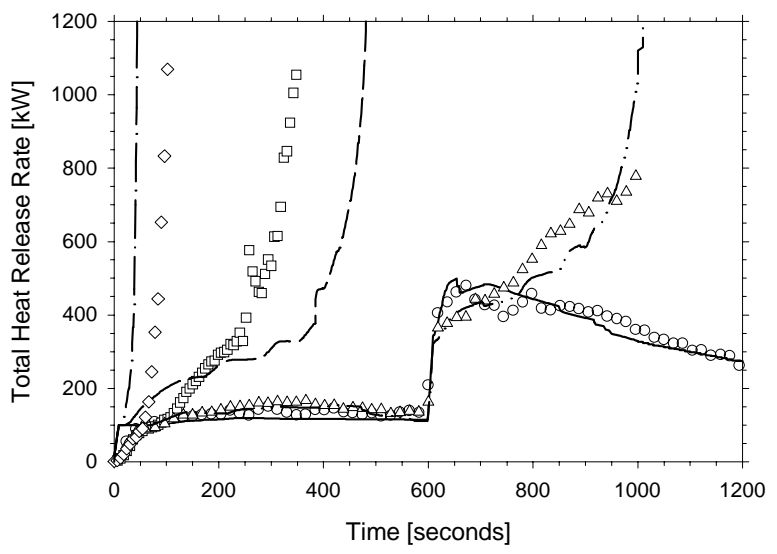

Figure 2. Measured and predicted total heat release rate in ISO 9705 tests on different materials. Material No. 1 [O (data), — (model)], Material No. 3 [ $\square$ (data), - - (model)], Material No. $5[\triangle($ data $),-\cdots-($ model $)]$, Material No. $7[\diamond($ data $),-\cdots$ (model) $]$. Data from Reference [15]. 


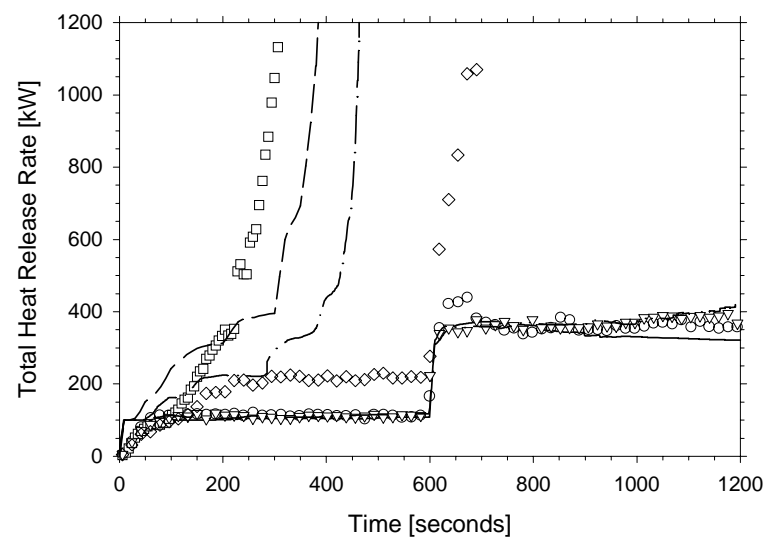

Figure 3. Measured and predicted total heat release rate in ISO 9705 tests on different materials. Material No. 2 [O (data), — (model)], Material No. 4 [ $\square$ (data), - - (model)], Material No. $6[\nabla($ data $),-\cdots-($ model $)]$, Material No. $8[\diamond($ data $),-\cdots($ model $)]$. Data from Reference [15].

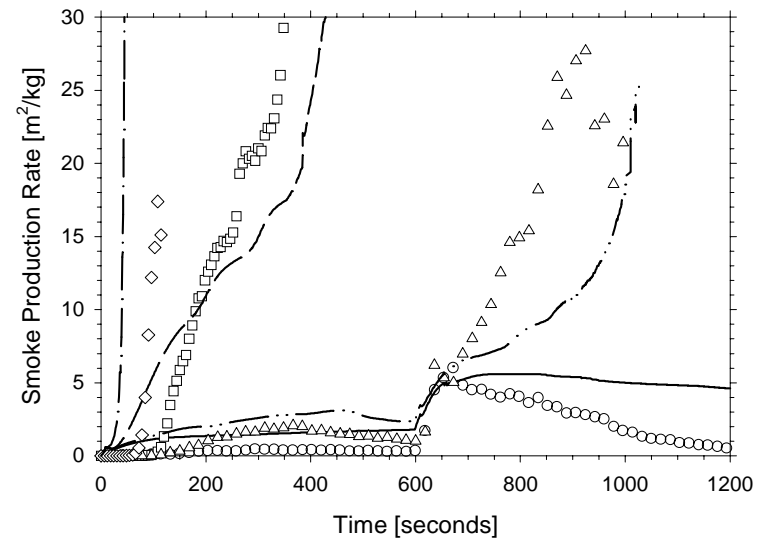

Figure 4. Measured and predicted smoke production rate in ISO 9705 tests on different materials. Material No. 1 [O (data), — (model)], Material No. 3 [ $\square$ (data), - - (model)], Material No. 5 [ $\triangle$ (data), - - - (model)], Material No. 7 [ $\diamond$ (data), - - (model)]. Data from Reference [15].

the test average values were more accurately predicted than the maximum 30 second average values. Smoke production rates were not as accurately predicted but do provide a sense for the magnitude of the smoke production rate during the ISO 9705 test. Again, test average values were more accurately predicted than the maximum 60 second average value.

Time histories of the predicted and measured [15] heat release rates are shown in Figs. 2 and 3. In general, there was good agreement between the model results and the data. The model accurately predicted the heat release rate for better performing materials, such as Material Nos. 1, 2, and 6. For poorer performing materials such as Material No. 7 (Fig. 2), the model tended to overpredict the measured heat release rate. For materials with performance between the worst and the best, the model could not always accurately predict the time history heat release rate curve, but the general trend in the heat release rate was well predicted. 
Time histories for the predicted and measured [15] smoke production rates are shown in Figs. 4 and 5. For these pre-flashover fires, smoke production rates are dependent on the amount of boundary material burning. In these tests, smoke production rates tended to have trends similar to the heat release rate of the fire. The model accurately predicted the heat release rate of Materials No. 1, 2 and 6 , but tended to overpredict the smoke production rates for these materials. For other materials, the predicted levels were typically conservative and the general trends in the smoke production rate were well predicted.

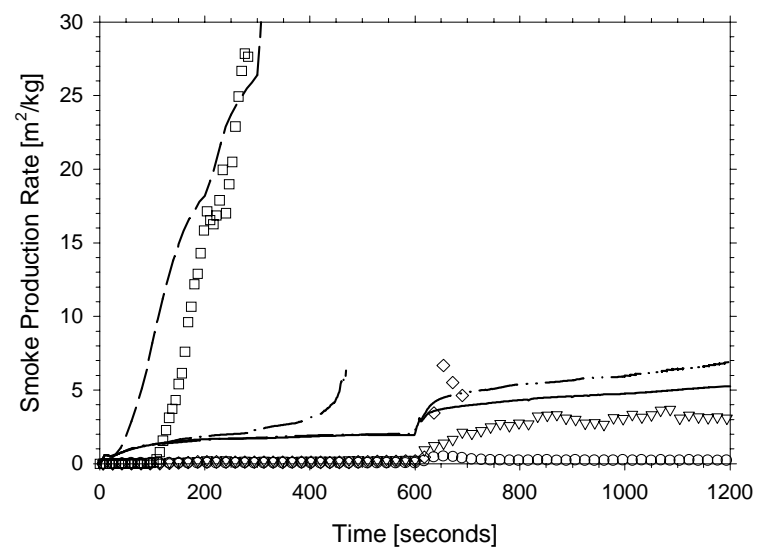

Figure 5. Measured and predicted smoke production rate in ISO 9705 tests on different materials. Material No. 2 [O (data), — (model)], Material No. 4 [ $\square$ (data), - - (model)], Material No. $6[\nabla$ (data), - - - (model)], Material No. $8[\diamond($ data $),-\cdots$ (model)]. Data from Reference [15].

\section{CONCLUSIONS}

The fire growth model described in this paper has been shown to successfully predict the conditions inside a compartment lined with a combustible material. To predict the contribution of the combustible lining, the model required input data developed from small-scale tests conducted in the ASTM E1354 cone calorimeter. The fire growth model was evaluated by comparing the model results with eight ISO 9705 large-scale room corner tests on materials having a range of fire performance. Predicted heat release rates compared well with experimental data, and the model was able to predict the occurrence of flashover typically to within \pm 135 seconds. Predicted smoke production rates compared favorably with the time history data and in general provided a conservative estimate of the smoke production rate. The fire growth model could be used to screen combustible lining performance in an ISO 9705 large-scale room corner test, which is required by IMO, USCG, and other organizations to regulate flammability and smoke production of lining materials. This screening can be performed using small-scale test data from ASTM E1354. The model has been shown to accurately predict the test average and maximum 30 second average heat release rate. Though smoke production rates were not as accurately predicted, the predicted levels were typically conservative and do provide an indication of the magnitude of the smoke production rates expected in the ISO 9705.

\section{ACKNOWLEDGEMENTS}

This work was funded by the U.S. Coast Guard Research and Development Center under Grant No. DTCG39-99-F-E00159. 


\section{REFERENCES}

1. Beyler, C.L., Hunt, S.P., Lattimer, B.Y., Iqbal, N., Lautenberger, C., Dembsey, N., Barnett, J., Janssens, M., Dillon, S., and Greiner, A., "Prediction of ISO 9705 Room/Corner Test Results," U.S. Coast Guard Final Report, R\&DC-215-99, 1999.

2. ISO 9705:1993(E), "Fire Tests - Reaction to Fire - Full-Scale Room Test for Surface Products," International Organization for Standards, Geneva, Switzerland, 1993.

3. ASTM E 1354-97, "Standard Test Method for Heat and Visible Smoke Release Rate for Materials and Products Using an Oxygen Consumption Calorimeter," 1997 Annual Book of ASTM Standards, Vol. 04.01: Building Seals and Sealants; Fire Standards; Dimension Stone, American Society for Testing and Materials, Philadelphia, PA, 1997, pp. 649-666.

4. Lattimer, B.Y., Hunt, S.P., Sorathia, U., Blum, M., Gracik, T., McFarland, M., Lee, A., and Long, G., "Development of a Model for Predicting Fire Growth in a Combustible Corner," Naval Surface Warfare Center Technical Report NSWCCD-TR-64-99/07, 1999, 200 p.

5. Beyler, C.L., Hunt, S.P., Iqbal, N., and Williams, F.W., "A Computer Model of Upward Flame Spread on Vertical Surfaces," Fire Safety Science - Proceedings of the Fifth International Symposium, Interscience Communications, London, UK, 1997, pp. 297-308.

6. Peacock, R.D., Forney, G.P., Reneke, P., Portier, R., and Jones, W.W., 1993, "CFAST, The Consolidated Model of Fire Growth and Smoke Transport," National Institute of Standards and Technology Technical Note 1299, Gaithersburg, MD, February 1993.

7. Kokkala, M., "Characteristics of a Flame in an Open Corner of Walls," Proceedings from Interflam '93, 1993, pp.13-24.

8. Markstein, G.H. and DeRis, J., "Wall-Fire Radiant Emission - Part 2: Radiation and Heat Transfer from Porous-Metal Wall Burner Flames," Twenty-Fourth Symposium (International) on Combustion, The Combustion Institute, pp. 1747-1752, 1992.

9. Alpert, R.L., "Turbulent Ceiling Jet Induced by Large-Scale Fires," Combustion Science and Technology, 11:197-213, (1975).

10. Hasemi, Y., Yoshida, M., Takashima, S., Kikuchi, R., and Yokobayashi, Y., "Flame Length and Flame Heat Transfer Correlations in Corner-Wall and Corner-Wall-Ceiling Configurations," Proceedings of INTERFLAM '96, 1996, pp. 179-188.

11. Hasemi, Y., Yoshida, M., Yokobayashi, Y., and Wakamatsu, T., "Flame Heat Transfer and Concurrent Flame Spread in a Ceiling Fire," Fire Safety Sceince - Proceedings from the Fifth International Symposium, Interscience Communications, London, UK, 1997, pp. 379-390.

12. Tanaka, T., Nakaya, I., and Yoshida, M., "Full Scale Experiments for Determining the Burning Conditions to be Applied to Toxicity Tests," Fire Safety Science-Proceedings of the First International Symposium, Interscience Communications, London, UK, 1985, pp.129138.

13. Mitler, H.E. and Steckler, K.D., "SPREAD - A Model of Flame Spread on Vertical Surfaces," National Institute of Standards and Technology NISTIR 5619, Gaithersburg, Maryland, 1993, $65 \mathrm{p}$.

14. Seader, J.D. and Einhorn, I.N., "Some Physical, Chemical, Toxicological and Physiological Aspects of Fire Smokes," Sixteenth Symposium (International) on Combustion, The Combustion Institute, Pittsburgh, PA, 1976, pp. 1423-1445.

15. Janssens, M. L., Garabedian, A., and Gray, W., "Establishment of International Standards Organization (ISO) 5660 Acceptance Criteria for Fire Restricting Materials Used on High Speed Craft," U.S. Coast Guard, Final Report, CG-D-22-98, 1998.

16. Resolution MSC.40(64), "Standard for Qualifying Marine Materials for High Speed Craft as Fire-Restricting Materials,” International Maritime Organization, London, 1994. 